\title{
trabalhonecessário
}

issn: $1808-799 \mathrm{X}$

ano 3 número $3-2005$

\section{AS CONTINUIDADES E AS DESCONTINUIDADES DA EDUCAÇÃO SUPERIOR NO BRASIL: \\ AS REFORMAS DO ENSINO SUPERIOR NO GOVERNO MILITAR E NO GOVERNO NEOLIBERAL}

Leandra Porto da Mata*.

\begin{abstract}
A sociedade capitalista em que vivemos, veio e vem procurando utilizar-se da instituição escolar para transmitir ao (futuro) trabalhador somente o conhecimento considerado necessário para a continuação do processo de produção em benefício da classe dominante. Mas, essa instituição, mesmo que seja um elemento determinado por essa sociedade, não deixa de influenciar a mesma, podendo tornar-se um instrumento importante e decisivo no processo de transformação da sociedade capitalista.
\end{abstract}

No modo de produção capitalista, o conhecimento sistematizado, a ciência, se transforma em força produtiva, isto é, em meio de produção. É aí que surge uma contradição do capitalismo: se o conhecimento é um meio de produção, ele deveria ser uma propriedade privada exclusiva da classe dominante; no entanto, o trabalhador não pode ficar totalmente desprovido do conhecimento, porque sem ele não terá como produzir, trabalhar e acrescentar valor ao capital (Saviani, 2003b, p.137).

A partir do pensamento pedagógico de Dermeval Saviani, e sua teoria educacional crítica dos conteúdos ${ }^{1}$, a escola pode e deve engajar-se na luta contra essa marginalização do conhecimento aos trabalhadores, garantindo-lhes um ensino de melhor qualidade possível nas condições históricas atuais, evitando que o conhecimento seja apropriado e articulado aos interesses da classe dominante. Nas palavras de Saviani, "o dominado não se liberta se ele não vier a dominar aquilo que os dominantes dominam. Então, dominar o que os 
dominantes dominam é condição de libertação" (Saviani, 2003a, p.55). Só dominando os mesmos conteúdos culturais da classe dominante, é que os trabalhadores poderão fazer valer os seus interesses, utilizando-os em função do bem comum.

Neste caso, estaremos refletindo especificamente sobre o rumo ao qual tem se direcionado a educação superior no Brasil mediante as reformas e mudanças pelas quais tem passado, procurando compreender a lógica de sua expansão e a sua inclusão no processo de mercantilização da educação.

\section{As reformas da educação superior no governo militar (1964-1985).}

O capitalismo mundial nesse período vivenciou o seu auge. No Brasil, foi nesse período, pós-64, que o Estado tornou-se o principal meio de estabelecimento e consolidação dos interesses do grande capital, em especial o multinacional, tornando o capital o maior beneficiado. Mais uma vez, como em qualquer sociedade capitalista, o Estado tem sido o lugar de expressão e consolidação dos interesses da classe hegemônica.

O binômio "Segurança e Desenvolvimento" era considerado o princípio norteador do período, e este por sua vez é um conceito-chave para se compreender a ação do Estado brasileiro nessa época determinada.

A segurança, considerada pelo governo da época como condição necessária para o desenvolvimento nacional, era necessária no sentido de manter a "ordem" para que ocorresse o tão almejado desenvolvimento econômico e social da Nação. O que se queria era uma segurança do capital, que só poderia acontecer através da ordem social, afinal, essa é de suma importância para a manutenção da exploração dos trabalhadores sem que esses façam qualquer tipo de contestação. O Estado tinha que disciplinar as classes subalternas para assegurar a implantação do capitalismo (Rodrigues, 1987).

O desenvolvimento também era considerado outra meta principal para a condição de progresso do país, e é desta maneira que a educação passa a desempenhar um importante papel. Na função de gerir e promover o sucesso do projeto político de desenvolvimento, ela passa a exercer a função de "aparelho ideológico do Estado", através da formação de mentalidades e de recursos humanos (a mão-de-obra). Nos diversos níveis da educação, podemos perceber a ideologia desenvolvimentista presente, objetivando a formação de trabalhadores capazes de produzir mais a um custo menor. Investe-se no desenvolvimento das inovações tecnológicas e adota-se uma perspectiva economicista em relação à educação, colocando o planejamento desta para ser exercido por economistas.

Dessa maneira, a educação ganha uma significativa responsabilidade pelo sucesso do projeto econômico e social do país. Portanto, juntamente com o ganho de tal importância, o Estado passa também a exercer um severo controle político-ideológico na educação, principalmente no âmbito do nível universitário, onde grupos ligados ao novo regime 
instaurado buscavam vincular o ensino superior ao mercado e ao projeto político de modernização de acordo com os requerimentos do capitalismo internacional.

A educação teve que se ajustar à ruptura política ocorrida com o golpe e, assim, durante 0 governo militar ela teve como atribuição a função de formar o capital humano, estando vinculada ao mercado de trabalho, e moldada pela ideologia desenvolvimentista e de segurança nacional. Durante esse período, as políticas públicas para educação eram associadas a discursos de "construção social" e a proposta de fortalecimento do Estado, que por sua vez foi reorganizado visando a atender os interesses econômicos vigentes. $E$ se o Estado foi reorganizado a Educação também precisava se reorganizar, e foi desta forma que se procurou adaptar o sistema educacional aos imperativos de uma concepção econômica de desenvolvimento, transformando educador e educando em mercadorias que, se forem bem investidas e moldadas, darão grandes lucros (Shiroma et al, 2002).

Com o avanço e o desenvolvimento do capitalismo no Brasil, a necessidade de mão-deobra qualificada ampliou-se juntamente com a necessidade de expansão da educação escolar.

No que tange ao ensino superior, esse se expandiu grandemente, principalmente o de caráter privado que recebeu considerável incentivo do governo, até mesmo através de verbas públicas; em 1973, chegaram a receber $39 \%$ dos recursos públicos do ensino superior (Cunha, 1988, p.74). O ensino superior também se tornou uma relevante estratégia para a reprodução e ampliação da chamada classe média, considerada de suma importância como mercado consumidor no modelo de desenvolvimento econômico da época. E desse modo "era necessário despolitizar o campo acadêmico, neutralizar as ações de contestação do movimento estudantil, ligado a organizações populares, e mantêlo sob rígido controle" (Germano, 1993, p.104).

As instituições de ensino superior no Brasil sofreram profundas fragmentações em sua organização interna; as universidades passaram a ser um problema constante, os militares partiram para a ação direta de intervenção, e para isso foi promulgado o Decreto no 62.024, em 1967, que instituía uma comissão especial para sanar esses "problemas".

O Relatório Meira Mattos, resultado dessa comissão, levou três meses para ficar pronto, possuindo as seguintes características: o Presidente da República escolheria os reitores e os diretores das universidades e faculdades federais, que deveriam se responsabilizar pela disciplina nesses estabelecimentos; pretendia-se retirar do movimento esquerdista a participação estudantil; sugere e possibilita a contratação de professores pela legislação trabalhista; e a adoção de créditos, que se não teve como objetivo a desmobilização estudantil, teve esta como considerável conseqüência, afinal com os estudantes dispersos é mais difícil de se organizarem os movimentos.

Nesse período o ensino superior sofreu várias influências norte-americanas; o governo da época acreditava que para modernizar o ensino superior brasileiro tinha que se basear no 
modelo norte-americano de universidade, para isso foram fornecidas 3.800 bolsas de estudos nos Estados Unidos da América para brasileiros, só no período de 1965/70 (todas, concedidas somente pela United States Agency for International Development - USAID). Vários acordos para o ensino superior foram feitos entre a USAID e o Ministério da Educação e Cultura (MEC), sendo os cursos de pós-graduação, criados na época, os maiores "beneficiados", mas o maior acordo feito, foi em junho de 1965 e ficou conhecido como o convênio MEC-USAID, que visava organizar uma equipe de assessoria ao planejamento do ensino superior, reunindo técnicos brasileiros e norte-americanos.

A "USAID encarava o ensino superior como elemento da formação de recursos humanos e estes como meios pra o aumento da produção industrial e da produção agrícola" (Cunha, 1988. p.168); também era importante estar no controle deste nível de ensino, pois é nele que se forma a maioria dos dirigentes do país.

Para a mudança do modelo universitário vigente, era necessário modificar a legislação que regulava este setor. Então, em 2 de julho de 1968, é baixado um decreto presidencial que instituía um Grupo de Trabalho no MEC, onde os 11 componentes desse grupo foram designados pelo presidente-general Artur da Costa e Silva, que estabeleceu um prazo de 30 dias para que o GT apresentasse um projeto de reforma universitária. O grupo iniciou o seu trabalho baseando-se nos estudos produzidos pelo convênio MEC-USAID e pelo Relatório Meira Mattos.

É importante relatar que a reforma universitária era uma luta de estudantes e de alguns professores, que não tiveram uma parte de suas propostas atendidas; o Governo, sob pressões de tendências desenvolvimentistas de âmbito nacional e internacional, resolveu tomar a liderança, até mesmo para assegurar o controle e a ordem; assim eles poderiam modernizar o ensino superior, como diz Romanelli (1986) sem romper com antigas tradições, nem ferir interesses conservadores, e, mais uma vez em nossa história política, o interesse social era substituído pela decisão de poucos. É necessário dizer que o governo militar não considerou necessário editar uma nova lei de diretrizes e bases por completo, por isso modificou somente o ensino universitário através da Lei 5.540/68, e mais tarde o ensino primário e secundário através da Lei 5.692/71.

Com a promulgação da Lei 5.540, em 28 de novembro de 1968, profundas mudanças aconteceram no ensino superior. A lei exigia que este deveria acontecer somente em universidades (baseadas no tripé ensino-pesquisa-extensão), sendo ministrado em estabelecimentos isolados (como faculdades) somente em casos excepcionais. Sabemos que não foi isso o que na realidade aconteceu, na verdade foram as universidades que se tornaram excepcionais, como podemos verificar na tabela abaixo.

\section{TABELA 1}


Instituições de ensino superior, segundo sua natureza organizacional.

\begin{tabular}{|c|c|c|c|}
\hline Anos & Universidades & $\begin{array}{c}\text { Estabelecimentos } \\
\text { Isolados }\end{array}$ & Total \\
\hline 1971 & 64 & 555 & 619 \\
\hline 1972 & 65 & 636 & 701 \\
\hline 1973 & 57 & 800 & 857 \\
\hline 1974 & 57 & 773 & 830 \\
\hline 1975 & 57 & 803 & 860 \\
\hline
\end{tabular}

Fonte: Anuários Estatísticos do Brasil (v. 33-39). 1972/1978. IBGE Tabela elaborada pela a autora.

Nas universidades, baseadas no ensino, pesquisa e extensão, deveriam ser criados cursos de graduação (que poderiam ser de curta ou longa duração), pós-graduação, extensão, aperfeiçoamento, especialização e pesquisa. Mas a estrutura organizacional desse tipo de ensino superior é muito dispendiosa, o que acarretou na criação de várias Faculdades (estabelecimentos isolados ou instituições similares), principalmente na esfera privada, já que essa estrutura é menos dispendiosa do que a estrutura em universidade. A maior parte do setor privado optou por esse último tipo de estabelecimento de ensino superior, o que possibilitou a esses estabelecimentos tornarem-se empresas altamente lucrativas.

As instituições privadas foram amplamente favorecidas por esse Governo, se expandindo muitíssimo nesse período, como podemos analisar na tabela a seguir, considerada por Cunha como uma expansão fragmentadora do ensino superior, já que essas instituições muitas vezes eram abertas sem as menores condições de proporcionar um ensino de boa qualidade, pois tinham bibliotecas e laboratórios de péssima qualidade, como professores que não possuíam uma boa formação. Essas empresas de ensino visavam somente o lucro, não se importando com a qualidade do ensino ou com a formação de seus alunos enquanto sujeitos críticos.

\section{TABELA 2}

Instituições de ensino superior, segundo sua natureza administrativa.

\begin{tabular}{|l|l|l|l|l|l|}
\hline Anos & Federal & Estadual & Municipal & Particula & \\
\hline & & & & & \\
\hline
\end{tabular}




\begin{tabular}{|l|l|l|l|l|l|}
1971 & 53 & 80 & 51 & 435 & 619 \\
\hline 1972 & 55 & 74 & 52 & 520 & 701 \\
\hline 1973 & 56 & 85 & 85 & 631 & 857 \\
\hline 1974 & 47 & 78 & 77 & 628 & 830 \\
\hline 1975 & 46 & 82 & 87 & 645 & 860 \\
\hline
\end{tabular}

Fonte: Anuários Estatísticos do Brasil (v. 33-39). 1972/1978. IBGE. Tabela elaborada pela a autora

É importante lembrar, também, que a maioria dessas instituições de ensino superior privada era composta por estabelecimentos isolados; por exemplo, no ano de 1975, das 645 instituições privadas, 625 eram estabelecimentos isolados de ensino superior (Anuário estatístico do Brasil, 1977, v.38 / IBGE).

Outro fator de extrema importância para a expansão do ensino superior privado foi o Relatório Atcon. Contratado pelo MEC, no período de 1965/68, para planejar mudanças no ensino superior brasileiro. Baseando-se nos modelos norte-americanos, o professor norteamericano Rudolph P. Atcon disseminou muito bem a idéia de privatização deste nível de ensino, para ele a Universidade deveria ter autonomia acadêmica, científica, e principalmente financeira, livre da interferência estatal, devendo funcionar como se fosse uma empresa privada. O Relatório Atcon também teve importante influência na proposta de reforma universitária feita pelo GT.

Com toda essa expansão desenfreada do ensino superior privado, o número de graduados aumentou e o título acadêmico perdeu a grande importância que possuía anteriormente, agora existia um "exército de reserva" diplomado sem emprego e que começava a questionar a qualidade do ensino recebido, pressionando o Governo para envolver-se nessa discussão.

Dessa forma, a lógica do mercado capitalista mais uma vez é atendida, agora há um exército de força de trabalho bem qualificada que não teve a sua mobilidade social adquirida através da obtenção de empregos, já que as enormes diferenças salariais continuam ampliando a concentração de rendas nas mãos de uma minoria parcela da população. Nessa mesma lógica, observa-se que a qualificação da mão-de-obra aumenta a produtividade, mas não aumenta a quantidade de contratação de trabalhadores, o que colabora para o aumento da exploração do trabalhador e, conseqüentemente, da maisvalia.

O Brasil, por volta do final do regime militar, encontrava-se em uma grande crise, tanto financeira, quanto educacional; $60 \%$ da população brasileira estavam abaixo da linha da pobreza, o que evidenciava uma extrema necessidade de mudança no modelo político vigente. Com esses dados podemos perceber que a educação não foi capaz de promover todo o desenvolvimento esperado pela sociedade brasileira e apregoado pelo governo, tornando-se agora inevitável a necessidade de se redirecionar a legislação educacional. 


\section{As reformas da educação superior no governo neoliberal (1990-2002).}

Esse período possui como características fundamentais a política neoliberal e o processo de reestruturação do Estado. Estes foram iniciados durante o Governo Collor e intensificados a partir de 1995, com o Governo Fernando Henrique Cardoso. Nesse governo o processo de privatização foi acelerado, e o Estado passou a ter uma administração pública de caráter gerencial e flexível, voltada para o atendimento do cidadão consumidor e para o controle de resultados.

Inserido nesta nova ordem mundial, que é o neoliberalismo, o Brasil transforma-se no país das reformas e fica submetido ao figurino do capital desenhado pelos organismos

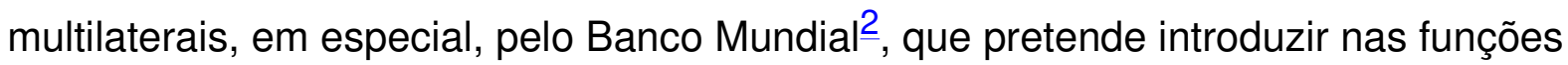
públicas os valores e critérios do mercado, disseminando a idéia de que todos devem pagar pelo que recebem.

Nesse contexto, o Brasil vem passando por um processo onde as tradicionais funções do Estado vêm sendo transferidas total ou parcialmente para o mercado, como já vem acontecendo com a saúde, a educação e a previdência privada; e é aí que se disseminam as empresas particulares dando origem a nova burguesia de serviços, como denomina BOITO Jr. (1999, p.67), da qual fazem parte essas instituições privadas de ensino superior que se expandem cada vez mais. Essa nova burguesia de serviços vem crescendo amplamente através da redução dos gastos e dos direitos sociais, dos inúmeros incentivos fiscais e dos diversos tipos de verba pública. Assim, é possível detectar "uma penetração ideológica e real do fazer mercantil em quase todos os espaços da vida e do ser humano" (SGUISSARDI \& SILVA Jr, 2001, p.261).

Toda essa política neoliberal que tem sido disseminada e implementada no Brasil, conforme a lógica capitalista, só vem fazendo os brasileiros a conviverem com: a privatização de vários órgãos públicos, a desvalorização da moeda (o real), o aumento da dívida interna e externa, o aumento do número de desemprego, a redução dos gastos sociais e a ampliação da concentração de renda.

Com relação ao ensino superior, este tem sido visto pelos organismos multilaterais como o motor do desenvolvimento econômico, que por sua vez tem sido cada vez mais adequado às exigências do mercado, transformando a aquisição do saber em um bem privado, especialmente da classe dominante.

Os organismos multilaterais, em especial o Banco Mundial, propõem uma série de mudanças para este nível de ensino, como a partilha de custos do ensino com os estudantes e suas famílias. E este fato já vem acontecendo devido ao fato de algumas Instituições de Ensino Superior públicas (IES) cobrarem dos seus alunos por cursos de pós-graduação e extensão. Essas cobranças de pagamento só retratam a contradição que há entre a prática cotidiana e a lei, já que tanto na LDB (artigo $3^{\circ}$, inciso VI), quanto na 
Constituição Federal (artigo 206), há a determinação da gratuidade do ensino público em estabelecimentos oficiais. Para o Banco Mundial, a maior parte dos recursos públicos deveria ser encaminhada para a educação básica, deixando o ensino superior para ser suprido pelas chamadas instituições não-estatais ${ }^{3}$ atuando conforme a lógica empresarial, pois para o BM, a democratização deste nível de ensino só acontecerá mediante a privatização das instituições, e países em desenvolvimento não precisam produzir conhecimento, tecnologia, mas somente comprá-los.

Não só o Estado, mas também o Ensino Superior têm passado por um amplo processo de reestruturação de cunho gerencialista ${ }^{4}$, acarretando vários tipos de mudanças no âmbito educacional.

A atual Lei de Diretrizes e Bases da Educação Nacional, de no 9.394/96, é um exemplo desse novo processo, já que por sua vez é uma lei minimalista, flexível, genérica e contraditória por possuir duas tendências totalmente distintas e oscilar entre elas. Por um lado, há uma tendência centralizadora, e, por outro lado, existe uma tendência descentralizadora. Logo em seu artigo $2^{\circ}$, a lei transfere a responsabilidade de prover a educação em primeiro momento para a família deixando esse dever em segundo plano para o Estado, o que, de certa forma, contradiz a Constituição Federal que responsabiliza primeiramente o Estado. Assim, a LDB dá uma base legal para que uma futura série de reformas seja fundamentada de acordo com os princípios defendidos pelos organismos multilaterais, como o Banco Mundial.

Então, os organismos multilaterais sugerem a distinção entre as universidades de ensino e de pesquisa, acreditando que esta deveria ser uma minoria, possibilitando, portanto, a reafirmação da estrutura dual no ensino.

Essa proposta de criação de dois modelos distintos de universidade é para adequar ainda mais o ensino superior às exigências do mercado. As "universidades de ensino", meras repassadoras de conhecimento, ficariam voltadas somente para o ensino e destinadas para a maioria da população, já que o mercado exige mão-de-obra cada vez mais qualificada e em um menor espaço de tempo. Para este tipo de ensino, a LDB criou os cursos seqüenciais de nível pós-médio e de curta duração (com dois anos de duração aproximadamente), encontrado-se, não por acaso, a maioria deles nas IES privadas. As universidades de ensino, então, passam a atender a lógica do mercado capitalista e não ao trabalhador, mais uma vez, pois este com sua especialização fragmentada, oriunda desse sistema de ensino que não o prepara para mantê-lo no mercado, acaba se encontrando em certo momento com sua preparação profissional em obsoleto devido à avançada tecnologia, tornando-se mais um desempregado a compor o "exército de reserva" tão necessário para o aumento do lucro das empresas capitalistas.

Enquanto isso, as "universidades de pesquisa", destinadas para uma pequena parcela da população, estariam desempenhando a função de promover o ensino, a pesquisa e a 
extensão, em suma, estariam produzindo o conhecimento. Esse tipo de ensino, sim, seria ministrado nas universidades que até hoje são pouquíssimas, como podemos ver no gráfico abaixo.

\section{GRÁFICO 1}

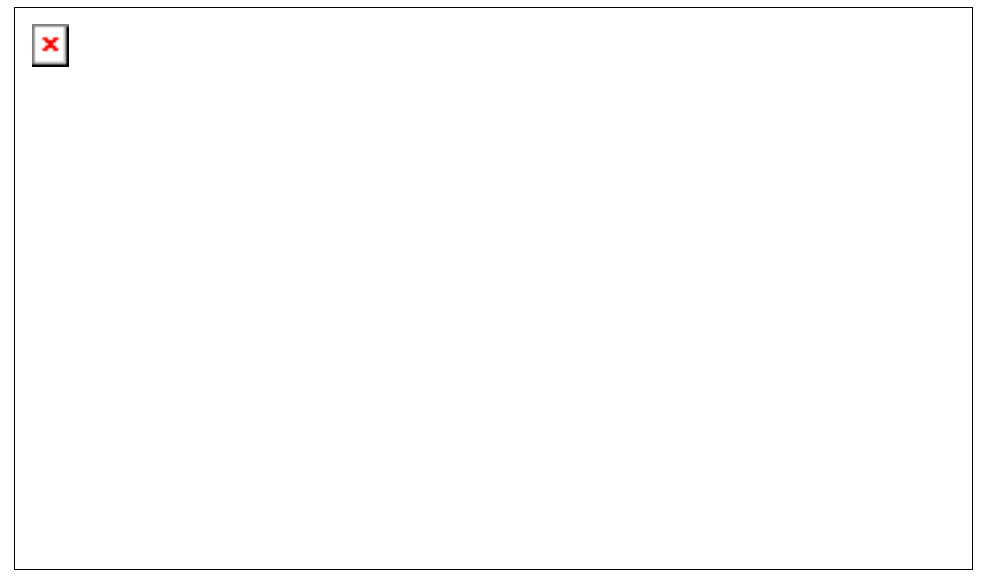

Devido a sua característica flexível, a LDB, em seu artigo 45, possibilita a diversificação das instituições superiores com seus variados graus de abrangência ou especialização. Com o Decreto de ํㅜ 3.860/2001, esse aspecto fica ainda mais comprovado, pois estabelece diversas classificações das instituições superiores que temos atualmente, que são: universidades; centros universitários; faculdades integradas, faculdades, institutos ou escolas superiores. Esse decreto agrupou esse último grupo em uma só classificação, fazendo que este não goze de autonomia, sendo obrigado a pedir autorização ao MEC a cada curso que abrir. Porém, o contrário aconteceu com os centros universitários que, de acordo com o Decreto citado acima (art. 11), possuem a mesma autonomia das universidades para criarem, organizarem e extinguirem, em sua sede, cursos e programas de educação superior, assim como remanejar ou ampliar vagas nos cursos existentes. Mas, apesar dos centros universitários possuírem os mesmos direitos das universidades, não possuem os mesmos deveres, como promover a pesquisa.

Além das instituições superiores citadas acima, ainda existem os Centros de Educação Tecnológica (CTE's) e os Centros Federais de Educação Tecnológica (CEFET's) que podem oferecer cursos de nível superior na área tecnológica, tendo como objetivo a formação de profissionais e especialistas dessa área (denominados de Cursos Superiores de Tecnologia - CST).

Outro fator de suma importância também, diz a respeito do investimento governamental no ensino superior público ${ }^{5}$ que vem sendo reduzido consideravelmente ${ }^{6}$, e na atual LDB não há nada dizendo que a União ou outro poder público tem a responsabilidade de criar novas instituições de ensino superior, o que acaba resultando na estagnação e na diminuição da sua expansão; a lei só trata em seu artigo 55 que a União deve manter as instituições de 
ensino por ela criada

No entanto, o contrário está acontecendo com as Instituições de Ensino Superior privadas que se expandem e aumentam a sua lucratividade devido a inúmeros benefícios concedidos pelo Estado, como a isenção de impostos, a isenção do salário-educação, e a isenção da contribuição previdenciária patronal das instituições filantrópicas ${ }^{7}$.

No gráfico a seguir podemos verificar claramente a expansão dessas instituições privadas se contrapondo consideravelmente com o número de instituições públicas.

\section{GRÁFICO 2}

Distribuição do número de instituições por natureza administrativa e organizacional (2001).

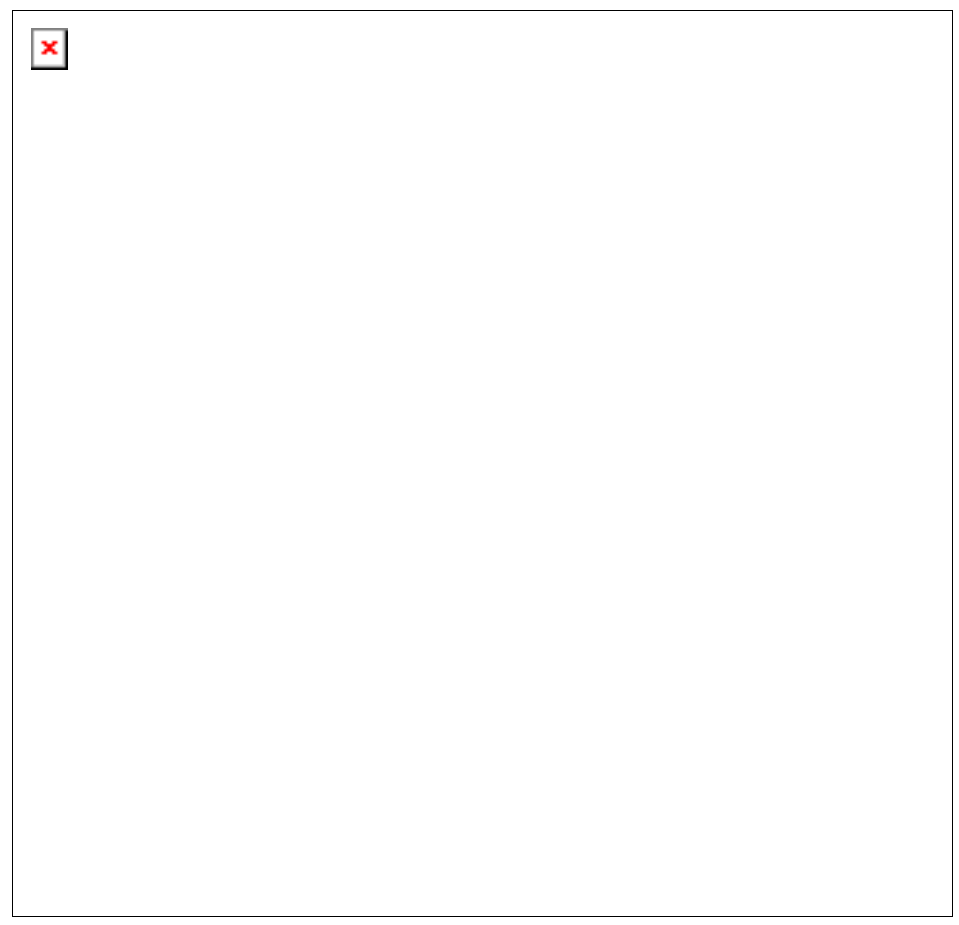

A liberdade de ação e a tentação do lucro fácil estão gerando no setor particular de ensino superior um quadro marcado pela inexistência das condições mínimas de trabalho, pesquisa e ensino, tornando as Universidades Privadas em "Mc Donald's" do ensino, que abrem seus cursos sem um controle de qualidade pelo Poder Público (nesse caso, o MEC). O crescimento quantitativo dessas instituições não tem sido acompanhado pelo crescimento qualitativo. Apesar da relevante expansão dessas IES privadas, podemos observar que normalmente a maioria delas está desassociada da tríplice função da universidade que é o ensino, pesquisa e extensão. Estas instituições se sujeitam às leis do mercado como uma grande empresa, onde o aluno é o cliente, e o dono da instituição é o dono do capital.

Com toda essa lógica mercantilista neoliberal, o ensino, principalmente o superior, tem se tornado uma importante mercadoria da nova burguesia de serviços ${ }^{8}$, que redireciona o ensino de acordo com a racionalidade capitalista. 
O ensino superior virou território de caça dos empresários do ensino, que vêm procurando adequar a universidade ao padrão de acumulação capitalista consagrado pelas classes dominantes, com base em um modelo econômico internacionalizado, concentrador e excludente.

\section{Continuidades ou descontinuidades da educação superior no Brasil?}

Podemos até vir a pensar, em uma rápida e primeira análise, que muita coisa mudou do período militar para o período neoliberal, mas, a questão é que, apesar de serem períodos distintos, e de terem formas de governo diferenciadas (um baseado na ditadura, e outro baseado na democracia), todos eles foram e são estruturados sob o modo de produção capitalista, o que os torna uma força "revolucionadora" permanente e contínua.

Como a borboleta que no início do seu desenvolvimento é apenas uma larva, que se transforma em lagarta para conseqüentemente se chegar à fase adulta, assim tem sido o ensino superior no capitalismo, possui fases distintas, que em muitas das vezes pensamos ser coisas totalmente opostas, mas que no fundo não são. Da mesma maneira que a lagarta parece ser um inseto totalmente distinto da borboleta, assim tem sido o desenvolvimento do ensino superior nesses governos capitalistas, possui fases que pensamos não ter nada a ver uma com a outra, mas que na verdade é apenas parte de seu próprio desenvolvimento.

Foi durante o governo militar que se iniciou e disseminou o germe da lógica mercantilista da educação, que tem se ampliado copiosamente no governo neoliberal; só possui o ensino aquele que pode pagar por ele. A educação, que antes era o lugar do ócio, se transformou e permanece sendo um grande negócio (Shiroma et al, 2002). E é assim que tem sido o ensino superior no Brasil, tem se desenvolvido cada vez mais de acordo com a lógica capitalista, que é a lógica do mercado.

E assim, plagiando o cantor Belchior, posso dizer que, apesar de acontecidas muitas "mudanças", ainda somos os mesmos e vivemos como os nossos pais. Foi necessário que tudo mudasse, para que tudo permanecesse como está.

\section{REFERÊNCIAS BIBLIOGRÁFICAS.}

BRASIL. Anuários Estatísticos do Brasil (v. 33-39). 1972/1978. IBGE.

Constituição da República Federativa do Brasil: promulgada em 5 de outubro de 1988. 33a edição. São Paulo: Saraiva, 2004.

Decreto $n^{\circ}$ 3.860, de 9 de julho de 2001. Dispões sobre a organização do ensino superior, a avaliação de cursos e instituições, e dá outras providências. . Informativo MEC. Brasília: MEC, № 1, julho, 2004.

. Lei no 5.540 , de 28 de novembro de 1968. Fixa normas de organização e funcionamento do ensino superior e sua articulação com a escola média, e dá outras providências. 
Lei oㅜ 5.692, de 11 de agosto de 1971 . Fixa Diretrizes e bases para o ensino de $1^{\circ}$ e $2^{\circ}$ graus, e dá outras providências.

. Lei de Diretrizes e Bases da Educação Nacional (LDBEN). Lei no 9.394, de 20 de dezembro de 1996.

MEC/INEP. Evolução da Educação Superior - Graduação - Anos 1980/1998. Disponível em:

http://www.inep.gov.br/dowloand/censo/1998/superior/evolução-1980-1998.pdf. Acesso em:

$14 / 11 / 2004$.

MEC/INEP. Sinopse estatística da educação Superior: 2002. Disponível em:

http://www.inep.gov.br. Acesso em: 14/11/2004.

BOITO JR., Armando. Política neoliberal e sindicalismo no Brasil. São Paulo: Xamã, 1999.

CUNHA, Luiz Antonio. A universidade reformanda. Rio de Janeiro: Francisco Alves, 1988.

DAVIES, Nicholas. O financiamento público às escolas privadas. In: NEVES, Lúcia Maria Wanderley (Org.). O empresariamento da educação: novos contornos do ensino superior no Brasil dos anos 1990. São Paulo: Xamã, 2002.

GERMANO, José Willington. Estado militar e educação no Brasil (1964-1985). São Paulo: Cortez, 1994.

RODRIGUES, Neidson. Estado, educação e desenvolvimento econômico. São Paulo: Autores Associados: Cortez, 1987.

ROMANELLI, Otaíza de Oliveira. História da educação no Brasil (1930-1973). Rio de Janeiro: Vozes, 1986.

SAVIANI, Demerval. Escola e democracia: polêmicas do nosso tempo. Campinas, São Paulo: Autores Associados, 2003a.

no1, 2003b.

O choque teórico da politecnia. Trabalho, Educação e Saúde. Rio de Janeiro: EPSJV-FIOCRUZ,

SGUISSARDI, Valdemar; SILVA JR., João dos Reis. Novas faces da educação superior no Brasil. São

Paulo: Cortez, 2001.

SHIROMA, Eneida Oto; MORAES, Maria Célia M. de; EVANGELISTA, Olinda. Política Educacional. Rio de Janeiro: DP\&A, 2002.

[*] Pós-graduanda em História Social do Brasil (UERJ), graduada em Pedagogia (UFF, 2005), professora da rede municipal de Niterói. leandra mata@ig.com.br

1. Para uma melhor discussão sobre teoria crítica dos conteúdos, chamada pelo autor de pedagogia revolucionária, ver Saviani (2003b).

2. Os cinco países que definem as políticas do Banco Mundial são: Eua, Japão, Alemanha, França e Reino Unido. Os EUA ocupam a presidência e possuem a maior parte dos recursos do Banco (Shiroma et al, 2002).

3. Instituição não-estatal é sinônimo de organização social. Segundo o Ministério da Administração e Reforma do Estado (MARE), as organizações sociais são propriedades públicas não-estatal, sem fins lucrativos que gozam de uma autonomia administrativa privilegiada, podendo fazer parte do orçamento público; não são propriedades de nenhum indivíduo ou grupo que estariam orientadas diretamente para o atendimento do interesse público, podendo submeter-se ao controle estatal, comunitário e do mercado. Essas organizações seriam uma resultante da união entre o Estado e a sociedade, e deverão manter-se financeiramente buscando apoio junto às empresas privadas. São para estas organizações que o Estado transfere a função que deveria exercer.

4. Segundo Bresser Pereira, ministro do MARE, os fundamentos da educação gerencial são: a descentralização; a definição dos objetivos de desempenho na forma quantitativa; o controle dos resultados administrativos, e não do processo; e a administração voltada para o atendimento do cidadão (Sguissardi \& Silva Jr, 2001).

5. O ensino superior público é composto pelo conjunto de IES formados pelo Poder Federal, Estadual e/ou Municipal. 
AS CONTINUIDADES E AS DESCONTINUIDADES DA EDUCAÇÃO SUPE... Página 13 de 13

6. O investimento da União para a educação vem sendo cada vez mais reduzido, em 1985 investia-se $6 \%$ do orçamento da União, e em 1995 somente 2,7\% desse orçamento (Jornal do Brasil, 15/3/03/1995. Fontes do IBGE e relatórios do Banco Central).

7. Para uma discussão aprofundada sobre essas isenções, ver Empresariamento da Educação (Davies, 2002).

8. Para um melhor aprofundamento sobre a nova burguesia de serviços, ver Boito Jr (1999).

volta

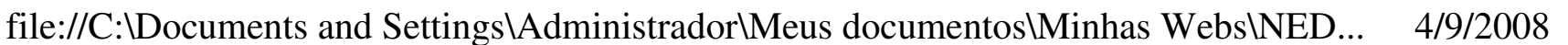

